\title{
Effect of anemia on pregnancy outcome: a prospective study at tertiary care hospital
}

\author{
Chintan Upadhyay ${ }^{1}$, Nisha Upadhyay ${ }^{2 *}$
}

\begin{abstract}
${ }^{1}$ Department of Obstetrics and Gynecology, GMERS Medical College and Civil Hospital, Gandhinagar, Gujarat, India
${ }^{2}$ Department of Pediatrics, GMERS Medical College and Civil Hospital, Gandhinagar, Gujarat, India
\end{abstract}

Received: 17 September 2017

Accepted: 27 October 2017

\author{
*Correspondence: \\ Dr. Nisha Upadhyay, \\ E-mail: drchintan1508@gmail.com
}

Copyright: () the author(s), publisher and licensee Medip Academy. This is an open-access article distributed under the terms of the Creative Commons Attribution Non-Commercial License, which permits unrestricted non-commercial use, distribution, and reproduction in any medium, provided the original work is properly cited.

\begin{abstract}
Background: Iron deficiency anaemia during pregnancy leads to preterm birth, low birth weight and small-forgestational age babies and increases incidence of postpartum haemorrhage (PPH) and the reason for the incidence of $\mathrm{PPH}$ is higher in India compared with the rest of the world. The objective of this study was to find association between maternal anaemia and neonatal complications and to find long term morbidity and mortality of babies born to anaemic mothers.

Methods: It is a prospective study done at Obstetrics and Gynecology Department, Dr. B. R. Ambedkar Medical College and Hospital, Bangalore during October 2009 to October 2011. All subjects were analyzed in full details and haemoglobin estimation done during $1^{\text {st }}$ visit, at $30^{\text {th }}$ week and $36^{\text {th }}$ week of gestation.

Results: Study observed moderate anaemia observed in almost 53.0\% cases followed by mild (29.5\%) and severe $(17.5 \%)$ respectively. Risk factors present in $58.0 \%$ cases and maternal complications in puerperium observed in $14.5 \%$ cases. High incidence of adverse foetal outcome in the form of preterm (20\%), IUGR (28\%), NICU admission $(25.5 \%)$ and IUD (3\%) seen in present study. Study found association between space between pregnancy, LSCS and fetal outcome with severity of anaemia. Ensuring maternal iron sufficiency during gestation is the most cost-effective method of preventing perinatal iron deficiency and related morbidities.

Conclusions: Iron supplementation during pregnancy in iron deficient mothers improves iron status during pregnancy and postpartum period, thus providing some protection against iron deficiency in the subsequent pregnancy. Proper antenatal care is the basic requirement for prevention, early detection and treatment of anaemia.
\end{abstract}

Keywords: Anemia, Fetal outcome, IUGR, LSCS, NICU, Space between pregnancies

\section{INTRODUCTION}

Anemia is crucial among all nutritional disorder in all over the world. ${ }^{1}$ More than $50 \%$ female in the world suffering from anaemia during their pregnancy. ${ }^{2-5}$ Developing countries like India has a big issue of anaemia in pregnancy and reported $87 \%$ prevalence of anemia in pregnancy. ${ }^{1}$

Iron deficiency anaemia during pregnancy leads to preterm birth, low birth weight and small-for-gestational age babies, and increases incidence of postpartum haemorrhage $(\mathrm{PPH})$ and this the reason for the incidence of $\mathrm{PPH}$ is higher in India compared with the rest of the world $^{6-8}$ Groups like women of child bearing age, pregnant women, preterm and low birth weight infants, older infants and toddlers and teenage girls are at higher risk of developing iron deficiency anaemia.

Children have low haemoglobin are at high risk of long term impairment in mental and motor development, lack of concentration, short attention span, easy distractibility, 
increased susceptibility to infection and abnormal appetite (pica). ${ }^{9}$ WHO categories Hb less than $110 \mathrm{~g} / \mathrm{L}$ as anemia in pregnancy. ${ }^{10}$ Many countries have made programmes of supplementing pregnant women with iron and folic acid with an aim that increasing the $\mathrm{Hb}$ levels has some beneficial effect. ${ }^{10}$ Several randomized control trials (RCTs) and meta-analyses have observed that routine iron supplementation is not of much use. ${ }^{11}$ Few of the studies have also shown that increase in the $\mathrm{Hb}$ beyond a certain level could in fact have a negative outcome. $^{12}$ Objective of present study was to find association between maternal anaemia and neonatal complications and to find long term morbidity and mortality of babies born to anaemic mothers.

\section{METHODS}

This prospective study was done among 200 pregnant women who were found to be anemic visited at Department of Obstetrics and Gynecology in Dr. B.R. Ambedkar Medical College and Hospital, Bangalore during October 2009 to October 2011. Data collection was done after ethical permission from institutional ethical committee and informed consent of clients.

All subjects were analyzed in full details and hemoglobin estimation done during $1^{\text {st }}$ visit, at $30^{\text {th }}$ week and $36^{\text {th }}$ week of gestation. Blood cultures were done in all the babies admitted to NICU for various reasons. Pre-tested questionnaire was administered and details like sociodemographic information, past history of medical illness, menstrual history was collected.

\section{Sample size and sampling}

A sample size of 200 was obtained using the hypothesis testing method and based on following assumptions: $95 \%$ confidence intervals, prevalence of anemia in pregnancy in India was $51.0 \%$ from the previous study and $7.5 \%$ allowable error. ${ }^{13}$ The calculated minimum sample has been inflated by $10 \%$ to account for anticipated subject non-response.

The investigations that done on these subjects were:

- Hemoglobin percentage: Quantitative estimation of hemoglobin was done by Sahli's method

- Peripheral smear: The type of anemia was studied by peripheral smear examination.

All the subjects were classified according to WHO criteria and according to degree of anemia all the subjects were treated with either oral iron or intravenous iron or blood transfusion and carefully followed in the antepartum, intrapartum and postpartum periods.

Finally, the modes of delivery, maternal and perinatal outcome were studied in all the study subjects. The data were recorded in an Excel sheet and descriptive analysis was performed, of which data are presented in the tables.

\section{RESULTS}

Table 1 shows that mean age of study participants was 25.4 years with 3.5 SD. Most numbers of participants $(46.5 \%)$ were belonged to 20 to 24 years age group followed by $34.0 \%$ in 25 to 29 years and $11.0 \%$ in less than 19 years respectively.

Table 1: Clinico-social information of study participants $(\mathrm{N}=\mathbf{2 0 0})$.

\begin{tabular}{|c|c|}
\hline Variable & Number (\%) \\
\hline \multicolumn{2}{|l|}{ Age (in year) } \\
\hline$\leq 19$ & $22(11.0)$ \\
\hline $20-24$ & $93(46.5)$ \\
\hline $25-29$ & $68(34.0)$ \\
\hline$\geq 30$ & $17(8.5)$ \\
\hline Mean age $($ mean $\pm S D)$ & $25.4 \pm 3.5$ \\
\hline \multicolumn{2}{|l|}{ Socio-economic status } \\
\hline Lower & $165(82.5)$ \\
\hline Middle & $35(17.5)$ \\
\hline \multicolumn{2}{|l|}{ Literacy status } \\
\hline Illiterate & $61(30.5)$ \\
\hline Primary & $85(42.5)$ \\
\hline Secondary & $44(22.0)$ \\
\hline Graduate and above & $10(5.0)$ \\
\hline \multicolumn{2}{|c|}{ Registration status pregnancy } \\
\hline Booked & $106(53.0)$ \\
\hline Un-booked & $59(29.5)$ \\
\hline Referred & $35(17.5)$ \\
\hline \multicolumn{2}{|l|}{ Parity } \\
\hline Primigravida & $66(33.0)$ \\
\hline Multi-gravida & $134(67.0)$ \\
\hline \multicolumn{2}{|c|}{ Spacing between pregnancy (in year) $(n=134)$} \\
\hline$<2$ & $79(59.0)$ \\
\hline$>2$ & $55(41.0)$ \\
\hline \multicolumn{2}{|l|}{ Risk factor } \\
\hline Present & $116(58.0)$ \\
\hline Absent & $84(42.0)$ \\
\hline \multicolumn{2}{|l|}{ Degree of anaemia } \\
\hline Mild & $59(29.5)$ \\
\hline Moderate & $106(53.0)$ \\
\hline Severe & $35(17.5)$ \\
\hline \multicolumn{2}{|l|}{ Mode of delivery } \\
\hline Vaginal & $131(65.5)$ \\
\hline LSCS & $69(34.5)$ \\
\hline \multicolumn{2}{|c|}{ Maternal complication in puerperium } \\
\hline Present & $29(14.5)$ \\
\hline Absent & $171(85.5)$ \\
\hline
\end{tabular}

Socio-economic status was measured by Kuppuswami classification and divided in two categories. Almost 82.5\% participants were in lower class. Around $42.5 \%$ participants were studied up to primary level followed by illiterate $(30.5 \%)$, secondary level $(22.0 \%)$ and graduation and above $(5.0 \%)$ respectively. only $53.0 \%$ cases were enrolled as registered cases and $17.5 \%$ were referred cases. 
Almost $67.0 \%$ cases were multi-gravida and $59.0 \%$ cases pregnant within less than 2 years of previous pregnancy. Present study observed pregnancy related risk factor like PE, PROM, oligohydramnios, hypothyroidism, Rh -ve, placenta previa, GDM, GHTN, abruptio placenta etc. Risk factor present in $58.0 \%$ cases and maternal complications in puerperium observed in $14.5 \%$ cases.

Table 1 shows that moderate anemia observed in almost $53.0 \%$ cases followed by mild (29.5\%) and severe $(17.5 \%)$ respectively.

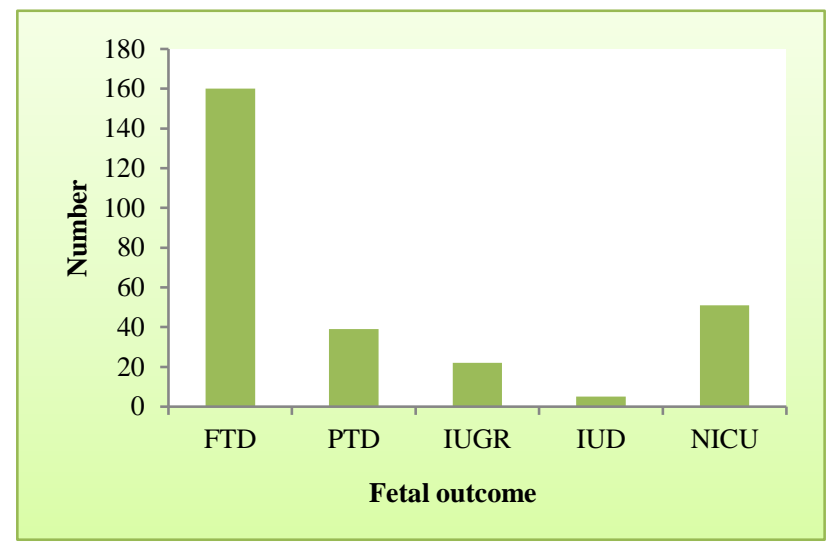

Figure 1: Feat outcome.

Figure 1 shows that high incidence of adverse fetal outcome in the form of preterm (20\%), IUGR (28\%), NICU admission (25.5\%) and IUD (3\%) seen in present study.

Table 2 shows that severe and moderate anaemia seen more among age group of 20-24 and 25-29 years respectively. This association was statistically significant $(\mathrm{p}<0.05)$.

Severe and moderate anaemia seen more among illiterate participants and less among literate participants and this association was statistically significant $(\mathrm{p}<0.05)$. Anaemia more seen among lower socio-economic class but and this association was not statistically significant $(\mathrm{p}>0.05)$.

Severity of anaemia seen more among un-registered pregnant participants and multigravida participants and this association was statistically significant $(\mathrm{p}<0.05)$. Present study observed statistically non-significant association between risk factor, space between pregnancy with severity of anaemia $(p>0.05)$.

LSCS observed more among participants with severe anaemia and this association was statistically significant $(p<0.05)$. Present study observed statistically significant association between foetal outcome with severity of anaemia $(\mathrm{p}<0.05)$ but not between birth weight and severity of anaemia $(\mathrm{p}>0.05)$.
Table 2: Association between socio-clinical characteristics with severity of anaemia $(\mathrm{N}=200)$.

\begin{tabular}{|c|c|c|c|c|}
\hline \multirow[t]{2}{*}{ Variable } & \multicolumn{3}{|c|}{ Severity of anaemia } & \multirow{2}{*}{$\begin{array}{l}P \\
\text { value }\end{array}$} \\
\hline & Mild & Moderate & Severe & \\
\hline \multicolumn{5}{|l|}{ Age } \\
\hline$\leq 19$ & 11 & 8 & 3 & \multirow{4}{*}{0.006} \\
\hline $20-24$ & 35 & 45 & 13 & \\
\hline $25-29$ & 11 & 40 & 17 & \\
\hline$\geq 30$ & 2 & 13 & 2 & \\
\hline \multicolumn{5}{|l|}{ Literacy } \\
\hline Illiterate & 8 & 31 & 22 & \multirow{4}{*}{0.0001} \\
\hline Primary & 31 & 48 & 6 & \\
\hline Secondary & 18 & 21 & 5 & \\
\hline $\begin{array}{l}\text { Graduate and } \\
\text { above }\end{array}$ & 2 & 6 & 2 & \\
\hline \multicolumn{5}{|c|}{ Socio-economic status } \\
\hline Lower & 47 & 87 & 31 & \multirow{2}{*}{0.539} \\
\hline Middle & 12 & 19 & 4 & \\
\hline \multicolumn{5}{|c|}{ Registration status } \\
\hline Booked & 37 & 60 & 9 & \multirow{3}{*}{0.009} \\
\hline Un-booked & 15 & 28 & 16 & \\
\hline Referred & 7 & 18 & 10 & \\
\hline \multicolumn{5}{|l|}{ Gravida } \\
\hline Primigravida & 28 & 31 & 7 & \multirow{2}{*}{0.012} \\
\hline Multigravida & 31 & 75 & 28 & \\
\hline \multicolumn{5}{|l|}{ Mode of delivery } \\
\hline Vaginal & 42 & 83 & 6 & \multirow{2}{*}{0.0001} \\
\hline LSCS & 17 & 23 & 29 & \\
\hline \multicolumn{5}{|l|}{ Risk factor } \\
\hline PE & 8 & 14 & 17 & \multirow{9}{*}{0.09} \\
\hline PROM & 8 & 17 & 10 & \\
\hline Oligohydramnios & 1 & 9 & 3 & \\
\hline Hypothyroidism & 3 & 1 & 1 & \\
\hline Rh-ve & 1 & 7 & 2 & \\
\hline Placenta PRV & 0 & 1 & 1 & \\
\hline GDM & 4 & 2 & 0 & \\
\hline GHTN & 0 & 4 & 2 & \\
\hline Abruptio placenta & 1 & 1 & 0 & \\
\hline \multicolumn{5}{|c|}{ Space between pregnancy } \\
\hline$<2$ & 14 & 47 & 18 & \multirow{2}{*}{0.37} \\
\hline$>2$ & 14 & 27 & 9 & \\
\hline \multicolumn{5}{|l|}{ Fetal outcome } \\
\hline FTD & 82 & 70 & 8 & \multirow{5}{*}{0.001} \\
\hline PTD & 6 & 24 & 9 & \\
\hline IUGR & 4 & 17 & 1 & \\
\hline IUD & 0 & 3 & 2 & \\
\hline NICU & 12 & 29 & 10 & \\
\hline \multicolumn{5}{|l|}{ Birth weight } \\
\hline$<2.5$ & 48 & 84 & 26 & \multirow{2}{*}{0.71} \\
\hline$>2.5$ & 11 & 22 & 9 & \\
\hline
\end{tabular}

\section{DISCUSSION}

Anaemia is a most prevalent issue in pregnant women in developing countries like India. Many similar studies observe variation in pregnancy outcome in anemic patients. ${ }^{13}$ In the present study 200 women were studied. The present study aimed at prevalence and management of anemia in pregnancy with maternal and fetal outcome. 
The various parameters of the subjects were studied, analyzed and evaluated with the standard literature reading available. In present study, $29.5 \%$ mild, $53 \%$ moderate and $17.5 \%$ were severely anemic. Majority of the anemic study subjects in the present study belonged to the age group of 20-24 years $(46.5 \%)$. This was comparable with the results of Alli $\mathrm{R}$ et al. ${ }^{14}$ The percentage of anemic women in his study was $40 \%$ in the same age group. Low socio-economic status is said to predispose to anemia, poor nutrition being the leading cause of anemia. In the present study, $82.5 \%$ of the anemic women belonged to the low socioeconomic group while $100 \%$ of women of the study of Alli R et al belong to the low socioeconomic group. ${ }^{15}$ Findings of the present study were also comparable with Rangnekar et al, in whose study $67 \%$ of anemic women belonged to low socio-economic group suggesting a close relationship between low socioeconomic conditions and pregnancy anemia. ${ }^{16}$

Effective and adequate antenatal care is essential for early identification and treatment of anemia. In present study $53 \%$ of women were booked cases. $29.5 \%$ and $17.5 \%$ were unbooked and referred cases respectively. In present study $74.2 \%$ had severe anemias in unbooked and referred cases were also comparable with Awasthi A et al $(83.5 \%) .{ }^{17}$ Anemia in pregnancy is more common in women of high parity due to frequent pregnancy and inadequate spacing. Mean spacing between births has an impact on the hemoglobin status of women. In present study spacing between pregnancy $<2$ years was $61.2 \%$ and $>2$ years in $38.8 \%$. It was comparable with Khandait DW et al, $55.9 \%$ and $44.1 \%$ in $<2$ years and $>2$ years respectively. ${ }^{18}$ Severity of anemia is positively associated with $<2$ years of spacing between two pregnancies with $\mathrm{p}=0.370$. A definitely association has been suggested between severe anemia and pregnancy induced hypertension. In the present study, $22.5 \%$ women had pregnancy induced hypertension. It was comparable with Awasthi A et al (24.5\%) and Sarin AR et al (28.5\%). ${ }^{17,19}$

The commonest type of anemia in the present study was Microcytic Hypochromic anemia $(82.5 \%)$ followed by Dimorphic anemia (17.5\%). Which was comparable with the study of Awasthi A et al (66.5\%), Rangnekar GA et al $(65 \%)$, Alli R et al $(68 \%){ }^{14,16,17}$ In the present study, $91.5 \%$ of subject received oral iron. $51.5 \%$ and $13.5 \%$ received parenteral (IV) iron and blood transfusion respectively. The requirement of blood transfusion were more in unbooked $(27.1 \%)$ and referred $(31.4 \%)$ cases compared to booked cases, which is statistically significant. Preterm deliveries (20\%), IUGR (11.5\%) and IUD $(3 \%)$ were the important maternal outcome in present study, which was comparable with the study of Sarin AR who observed that $31.2 \%$ women had preterm deliveries. High incidence of preterm deliveries, IUGR and IUD were seen in spacing between pregnancy $<2$ years. ${ }^{19}$ In present study, $90.6 \%$ of women had FT deliveries, high incidence of preterm deliveries $27.1 \%$ and $40 \%$ in unbooked and referred cases compare to booked, which were statistically significant. IUD was more seen in the referred $(11.4 \%)$ cases compared to booked cases, postpartum complication were also high in unbooked $(25.4 \%)$ and referred $(20 \%)$, which were also statistically significant.

High incidence of adverse fetal outcome in the form of preterm $(20 \%)$, IUGR (28\%), NICU admission $(25.5 \%)$ and IUD (3\%) seen in present study. These were comparable with the observation of Awasthi A et al PT (9.5\%), IUGR (37.5\%) and IUD $(8 \%)$ and also comparable with Rangnekar et al PT (73\%), IUGR (4\%) and IUD $(16 \%){ }^{16,17}$ In the present study, incidence of preterm deliveries in unbooked cases (27.1\%) and referred cases $(40 \%)$ were high compared with booked cases $(9.4 \%)$. High incidence of IUGR was seen in unbooked $(37.3 \%)$ and referred $(48.6 \%)$ cases compared with booked cases $(16 \%)$. As anemia predisposes to birth asphyxia due to placental insufficiency, need for NICU admission were more. Among those unbooked (33.9\%) and referred $(37.1 \%)$ required more NICU admission compared to booked (17\%) cases due to severe anemia. IUD was seen more in referred $(11.4 \%)$ cases with severe anemia and associated risk factors were severe preeclampsia, GDM and PROM. These all outcome were statistically significant. Incidence of low birth weight babies in the present study was $46.3 \%$ which was comparable with $66 \%$ observed by Rangnekar et al and $69.1 \%$ by Khalida $\mathrm{H}$ et al. ${ }^{16,20}$

One of the recent study done in Muscat by Angelitta J and all suggests that maternal age, parity and late prenatal visit were independently associated with maternal anemia, low birth weight and preterm birth. ${ }^{21}$

In 2010 one study done in India through a retrospective approach, 4,456 women's hospital record were reviewed and the result shows that $17.9 \%$ (798) of them were anemic, out of this $2.15 \%$ (96) of them were found to be severely anemic and six out of 96 women died due to severe anemia. ${ }^{22}$

Cochrane review 2009 shows that microcytic hypochromic anemia resulting from iron deficiency is the most frequent form of anemia $(76 \%)$, followed by folate deficiency $(20 \%)$ and combined iron and folate deficiency $(20 \%){ }^{11}$

\section{CONCLUSION}

Anemia is the commonest medical disorder in pregnancy which exist world over and is a very common problem in most of the developing countries. It is not only a medical problem, but is a major public health problem. In country like India, it is frequently severe and contributes significantly to maternal mortality and reproductive health morbidity. $60-80 \%$ of pregnant women in developing countries have anaemia and $40 \%$ of maternal deaths in the third world are related to anaemia. Among various causes of anaemia, $90 \%$ are nutritional in origin. 
Iron deficiency is the commonest nutritional anemia followed by folic acid deficiency.

Iron supplementation during pregnancy in iron deficient mothers improves iron status during pregnancy and postpartum period, thus providing some protection against iron deficiency in the subsequent pregnancy. Ensuring maternal iron sufficiency during gestation is the most cost-effective method of preventing perinatal iron deficiency and related morbidities. Joint social and medical efforts are required for overall improvement of living status of women. Proper antenatal care is the basic requirement for prevention, early detection and treatment of anaemia. Emphasis should be laid on prevention of anaemia by active participation of governmental and nongovernmental organizations, FOGSI, local societies etc.

\section{Funding: No funding sources}

Conflict of interest: None declared

Ethical approval: The study was approved by the Institutional Ethics Committee

\section{REFERENCES}

1. Kalaivani K. Prevalence and consequences of anemia in pregnancy. Indian J Med Res. 2009;130:627-33.

2. DeMaeyer, Adiels-Tegman M. The prevalence of anaemia in the world. World Health Statistics Quarterly. 1985;38(3):302-16.

3. Scholl TO. Iron status during pregnancy: setting the stage for mother and infant. Am $\mathrm{J}$ Clin Nutr. 2005;81(5):1218-22.

4. Looker AC, Dallman PR, Carroll MD, Gunter EW, Johnson CL. Prevalence of iron deficiency in the United States. J Am Med Assoc. 1997;277(12):9736.

5. Viteri FE. The consequences of iron deficiency and anaemia in pregnancy on maternal health, the foetus and the infant. SCN News. 1994;11:14-8.

6. Haider BA, Olofin I, Wang M. Nutrition Impact model study group (anaemia). Anemia, prenatal iron use, and risk of adverse pregnancy outcomes: systematic review and meta-analysis. $\mathrm{Br}$ Med $\mathrm{J}$. 2013;346:f3443.

7. Kavle JA, Stoltzfus RJ, Witter F, Tielsch JM, Khalfan SS, Caulfield LE. Association between anaemia during pregnancy and blood loss at and after delivery among women with vaginal births in Pemba Island, Zanzibar, Tanzania. J Health Popul Nutr. 2008;26:232-40.

8. Center for Reproductive Rights. Maternal mortality in India: using International and Constitutional Law to promote accountability and change. New York: Center for Reproductive Rights, 2008.
9. Shashtri DD. Commom issue in current concepts. Acedemic of Pediatrics, Gujarat. 2013:85-9.

10. Jaleel R, Khan A. Severe anemia and adverse pregnancy outcome. J Surg Pak. 2008;13:147-50.

11. Pena-Rosas JP, Viteri FE. Effects of routine oral iron supplementation with or without folic acid for women during pregnancy. Cochrane Database Syst Rev. 2006;(3):CD004736.

12. Koller O, Sagen N, Ulstein M, Vaula D. Fetal growth retardation associated with inadequate haemodilution in otherwise uncomplicated pregnancy. Acta Obstet Gynecol Scand. 1979;58:9-13.

13. Mangla M, Singla D. Prevalence of anaemia among pregnant women in rural India: a longitudinal observational study. Int J Reprod Contracept Obstet Gynecol. 2016;5:3500-5.

14. Alli R, Satyanarayana M. Anemia complicating pregnancy. J Obstet Gynecol India. 1985; 35(2): 335338.

15. Bhatt RV. Management of pregnancy anaemia: Obstetrician's dilemma. J Obstet Gynecol India. 1998;48(6):96-100.

16. Rangnekar AG, Rashmi D. Fetal outcome in pregnancy anemia. J Obstet Gynecol India. 1993;43(2):172-6.

17. Awasthi A, Thakur R, Dave A, Goyal V. Maternal and perinatal outcome in cases of Moderate and Severe anemia. J Obstet Gynecol India. 2001;51(6):62-5.

18. Khandait DW, Ambadikar NN, Zodpey PS. Risk factors for anemia in pregnancy. J Obstet Gynaec India. 2001;51(1):42-4.

19. Sarin AR. Severe anemia of pregnancy: recent experience. Int J Gynecol Obstet India. 1997;1(1):3944.

20. Khalida H, Shah GN, Farooq F. Some obstetric and fetal correlations in association with anemia in pregnancy. Indian $\mathbf{J}$ Maternal Child Health. 1997;8(2):48-50.

21. Angelitta JN, Alkhasawneh E, Seshan V, Raman S. Anemia in pregnancy: consequences and challenges: a review of literature. J South Asian Federation Obstet Gynecol. 2012;4(1):64-70.

22. Rohilla M, Ravenndran A, Dhaliwal LK, Chopra S, Severe anemia in pregnancy: a tertiary hospital experience from northern India. J Obstet Gynecol. 2010;30(7):694-6.

Cite this article as: Upadhyay $\mathrm{C}$, Upadhyay $\mathrm{N}$. Effect of anemia on pregnancy outcome: a prospective study at tertiary care hospital. Int $\mathbf{J}$ Reprod Contracept Obstet Gynecol 2017;6: 5379-83. 